\title{
Pattern of breathing during exercise in patients with interstitial lung disease
}

\author{
JGW BURDON, KJ KILLIAN, NL JONES
}

From the Department of Medicine, McMaster University, Hamilton, Ontario, Canada

ABSTRACT The responses to exercise were studied in 41 patients with pulmonary fibrosis, in whom vital capacity (VC) was reduced to $62 \%$ of predicted normal values. Maximum power output $\left(\mathrm{PO}_{\max }\right)$ was $53 \%$ predicted; there was a significant relationship between $\mathrm{PO}_{\max }$ and $\mathrm{VC}(\mathrm{r}=$ $0 \cdot 564)$. The maximum ventilation achieved during exercise was also related to $\mathrm{VC}(\mathrm{r}=0 \cdot 614)$. Although arterial oxygen saturation $\left(\mathrm{SaO}_{2}\right)$ fell by more than 5\% in 13 of 31 patients, there was no relationship between either $\mathrm{SaO}_{2}$ at $\mathrm{PO}_{\max }$ or the exercise related fall in $\mathrm{SaO}_{2}$ and $\mathrm{PO}_{\max }$. Heart rate responses were higher than normal predicted values in seven patients, all of whom showed a low $\mathrm{PO}_{\max }\left(36 \%\right.$ predicted); this finding was due only in part to a fall in $\mathrm{SaO}_{2}$. The ventilatory response to exercise was within normal limits for the patients as a whole; those subjects with the lowest $\mathrm{PO}_{\max }$ showed relatively higher ventilatory responses to exercise but the difference was not significant. The pattern and timing of breathing was studied in 32 patients and compared with control subjects matched by sex, age, and size. Tidal volume (VT) was low in the patients; maximum VT was related to $\mathrm{VC}(\mathrm{r}=0.761)$, but at low values of $\mathrm{VC} \mathrm{VT}_{\max }$ was higher than in healthy subjects with comparable VC. The total breathing cycle time (Ttot) fell with progressive exercise in patients and controls; Ttot for a given ventilation was shorter in the patients. Inspiratory time ( $\mathrm{Ti}$ ) was shorter in patients than controls, as was Ti/Ttot. In most patients with diffuse pulmonary fibrosis exercise is limited by a reduced ventilatory capacity, despite the adoption of a short $\mathrm{Ti}$ and high inspiratory flow rate, both of which serve to optimise tidal volume and breathing frequency and presumably reduce both the force developed by inspiratory muscles and the sensation of breathlessness.

Measurement of the ventilatory responses to exercise provides useful information about the functional reserve capacity of the lungs and the control of breathing in healthy people and patients with pulmonary disease.' ${ }^{\prime}$ Patients with interstitial pulmonary disease (alveolitis and fibrosis) characteristically are dyspnoeic during exercise, and have a limited pulmonary reserve owing to mechanical and gas exchange abnormalities. There have, however, been few systematic studies of the exercise responses in these conditions. ${ }^{2}$ To meet the ventilatory demands of exercise the intensity, duration, and frequency of force development in the respiratory muscles must alter to oppose the increased impe-

Address for reprint requests: Dr NL Jones, Ambrose Cardiorespiratory Unit, McMaster University Health Sciences Centre, 1200 Main Street West, Hamilton, Ontario, Canada.

Accepted 21 June 1983 dance. This report presents the results of standardised exercise studies carried out in 41 patients with various interstitial lung diseases. Our major aim was to define abnormalities of the pattern and timing of breathing; for this reason we measured the mean time spent in inspiration $(\mathrm{Ti}$, the duration of inspiratory flow), the total duration of the respiratory cycle (Ttot), and the relationship of $\mathrm{Ti}$ to Ttot (the proportion of each breath duration which is spent in force development-the inspiratory "duty cycle" ${ }^{34}$ ).

\section{Methods}

From 1972 to 198141 patients under investigation for interstitial lung disease took part in exercise studies as part of the pulmonary function assessment. Patients were accepted as having interstitial lung disease provided that they fulfilled the following criteria: (1) a diagnosis confirmed by lung biopsy 
or a clinical course consistent with interstitial lung disease; (2) chest radiographs characteristic of interstitial lung disease; (3) vital capacity less than $80 \%$ of the predicted value; (4) absence of clinical or spirometric evidence of airflow obstruction, ischaemic heart disease, or other conditions affecting exercise capacity.

The 41 patients ( 24 males, 17 females) had an age range of 13-75 years (mean 46 (SD 13) years). Mean (SD) spirometric indices were: vital capacity 2.33 (SD 0.71) litres (62\% (15\%) predicted) and $\mathrm{FEV}_{1}$ /VC ratio $83 \%$ (10\%). Predicted values were taken from Morris et al. ${ }^{5}$ Diagnoses included cryptogenic fibrosing alveolitis (17 patients); pulmonary sarcoidosis (11); collagen vascular disorders (5); hypersensitivity pneumonitis (4); and eosinophilic granuloma (4).

Standard methods of exercise testing and spirometric measurement were used throughout the survey period and calibration of equipment and quality control was a regular routine. ${ }^{6}$ Spirometric indices and exercise test results were taken from the laboratory report sheets except for inspiratory and total breath duration, which were measured from the original exercise test recordings. These were unavailable in nine patients. Thus complete data were obtained for only 32 patients; but the mean age, size, and spirometric variables in this group (table 1) were virtually identical to those of the total group of 41 patients.

To provide comparisons for the exercise responses, healthy subjects were selected from over 100 who had taken part in a study in our laboratory, each patient being matched with a healthy subject of the same sex, age ( \pm 5 years), and height $( \pm 5 \mathrm{~cm})$ (table 1).

Spirometric measurements were made with a 13.5 litre Collins water sealed spirometer or dry spirometer (Vitalograph). The best of three measurements was taken as the forced expiratory volume in one second $\left(\mathrm{FEV}_{1}\right)$ and vital capacity (VC). Exercise tests were performed on an electrically braked

Details of 32 patients and 32 control subjects

\begin{tabular}{llllll}
\hline & $\begin{array}{l}\text { Age } \\
(y)\end{array}$ & $\begin{array}{l}\text { Height } \\
(\mathrm{cm})\end{array}$ & $\begin{array}{l}F E V_{1} \\
(l)\end{array}$ & $\begin{array}{l}V C \\
(l)\end{array}$ & $\begin{array}{l}\text { POmax } \\
(\mathrm{kpm} / \mathrm{min})\end{array}$ \\
\hline $\begin{array}{c}\text { Patients } \\
\text { Mean }\end{array}$ & 48 & 165 & 1.94 & 2.38 & 556 \\
SD & 14.3 & 18.1 & 0.61 & 0.78 & 248 \\
& & & & & \\
$\begin{array}{c}\text { Controls } \\
\text { Mean }\end{array}$ & 47 & 166 & 3.50 & 4.09 & 1050 \\
SD & 14.4 & 7.5 & 0.88 & 0.96 & 424 \\
\hline
\end{tabular}

FEV -forced expiratory volume in one second; VC-vital capacity; $\mathrm{PO}_{\max }$ - maximum power output.

Conversion: Traditional to SI units-Power output: $1 \mathrm{kpm} / \mathrm{min} \approx$ $0.16 \mathrm{w}$. cycle ergometer (Elema 380), care being taken to ensure that the height of the saddle and the position of the respiratory mouthpiece were comfortable. The exercise protocol followed was the "stage I" progressive incremental procedure routinely used in our laboratories for clinical exercise testing. ${ }^{6}$ After satisfactory resting measurements had been recorded an initial work load of 100 or $150 \mathrm{kpm} / \mathrm{min}$ $(16.4$ or $24.5 \mathrm{w})$ was used. The power output was subsequently increased in increments of 50 or 100 $\mathrm{kpm} / \mathrm{min}(8.2$ or $16.4 \mathrm{w})$ at the end of each minute, exercise being performed continuously. Subjects were asked to continue exercising for as long as possible. Throughout the test the subject breathed through a mouthpiece connected to a Lloyd valve having a combined dead space of $50 \mathrm{ml}$. Inspired ventilation ( $\left.\dot{V}^{\prime}\right)$ was measured with a dry gas meter (Parkinson Cowan CD4) fitted with a potentiometer. Measurements of $\dot{V} I$, tidal volume (VT), respiratory rate, $\mathrm{Ti}$, and total breath duration (Ttot) were made for 20 second averaged periods at each work load. In a separate study measurements of $\mathrm{Ti}$ made with a pneumotachograph and the dry gas meter showed a small delay in the gas meter response leading to a 5-10\% underestimation of $\mathrm{Ti} / \mathrm{Tt}$ tot, which was not influenced by changes in breathing pattern and was considered not to influence comparison between the patients and normal controls.

Arterial oxygen saturation $\left(\mathrm{SaO}_{2}\right)$ was monitored by ear oximetry' (Hewlett Packard) in 31 patients and recordings of $\mathrm{SaO}_{2}$ were made at the end of each power output.

The ventilatory response to exercise was assessed by calculating the group mean $\dot{V} I$ at each power output. Analysis of the pattern of breathing was undertaken by comparing the group mean VT, respiratory rate, $\mathrm{Ti}$, and $\mathrm{Ttot}$ for $10 \mathrm{l} / \mathrm{min}$ intervals of Vi. Predicted maximum power output was calculated from a standard regression equation. ${ }^{6}$

Linear relationships were determined by the method of least squares and compared by analysis of variance.

\section{Results}

Maximum power output $\left(\mathrm{PO}_{\max }\right)$ was reduced to below $80 \%$ of that predicted on the basis of sex, age, and size in all but one patient. In comparison with the matched control group of healthy subjects, the patients achieved only $53 \%$ of the maximum power output (table). Both the maximum power output (fig 1) and maximum ventilation (fig 2 ) were linearly related to the vital capacity.

Oxygen saturation $\left(\mathrm{SaO}_{2}\right)$ was measured during exercise in 31 subjects; significant reductions (grea- 


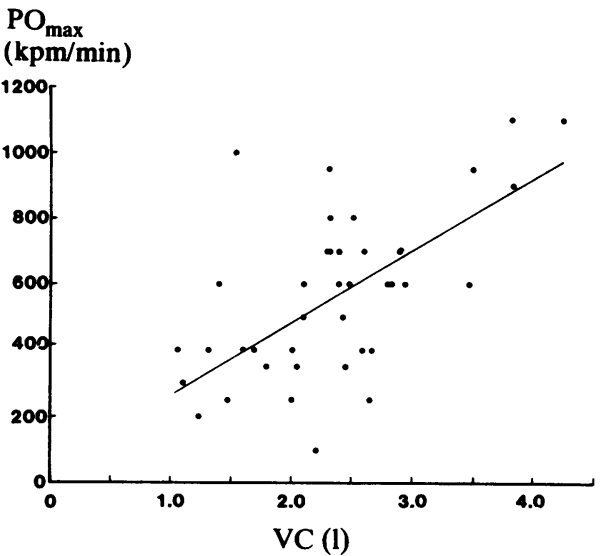

Fig 1 Maximum power output $\left(P O_{\max }\right)$ related to vital capacity $(V C)$. Regression equation: $P o_{\max }(\mathrm{kpm} / \mathrm{min})=$ $41+220$ VC $(r=0.564, p<0.05)$. Conversion:

Traditional to SI units-Power output: $1 \mathrm{kpm} / \mathrm{min} \approx$ $0 \cdot 16 w$.

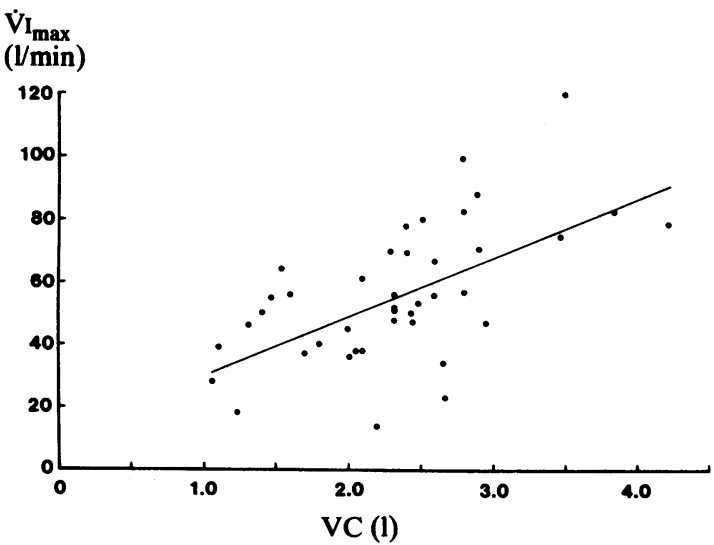

Fig 2 Ventilation at maximum power output related to vital capacity. Regression equation: $V_{I_{\max }}(l / \min )=12 \cdot 1+$ $18.9 V C(r=0.614, p<0.001)$

ter than $5 \%$ ) occurred in 13 patients. Neither $\mathrm{SaO}_{2}$ at $\mathrm{PO}_{\max }$ nor change in saturation during exercise $\left(\Delta \mathrm{SaO}_{2}\right)$ correlated with $\mathrm{PO}_{\max }$ expressed as a percentage of the predicted normal average value (fig 3).

The heart rate responses to exercise were within the expected normal range in all but seven patients. These seven showed a slightly greater reduction in VC (mean $49 \%$ (SD 13.6\%) predicted) and lower $\mathrm{PO}_{\max }$ (mean $378(71) \mathrm{kpm} / \mathrm{min}$ ) than the group as a whole and all but one showed a fall in $\mathrm{SaO}_{2}$ (mean fall 5\%).

Ventilation $(\dot{V} I)$ increased linearly with increasing power output in all subjects. The group mean ven- tilatory response to exercise was best described by the equation $\mathrm{VI}=9.29+0.07 \mathrm{PO}(\mathrm{r}=0.98)$, where $V_{I}$ is in $1 / \mathrm{min}$ and $P O$ in $\mathrm{kpm} / \mathrm{min}$. To ensure that no undue bias was placed on this relationship by subjects with low maximum power output (less than $50 \%$ predicted) the ventilatory response for these subjects $(n=14)$ was compared with those whose on exercise capacity was $50 \%$ predicted or more $(n=$ 27). Although $V_{I}$ in subjects with low maximum. power output was 5-10 $\mathrm{l} / \mathrm{min}$ higher at each power output (fig 4), this difference did not reach significance $(p=0 \cdot 27)$. Increases in VI during exercise were a result of increases in both VT and

$\mathrm{PO}_{\max }$

(\% predicted)

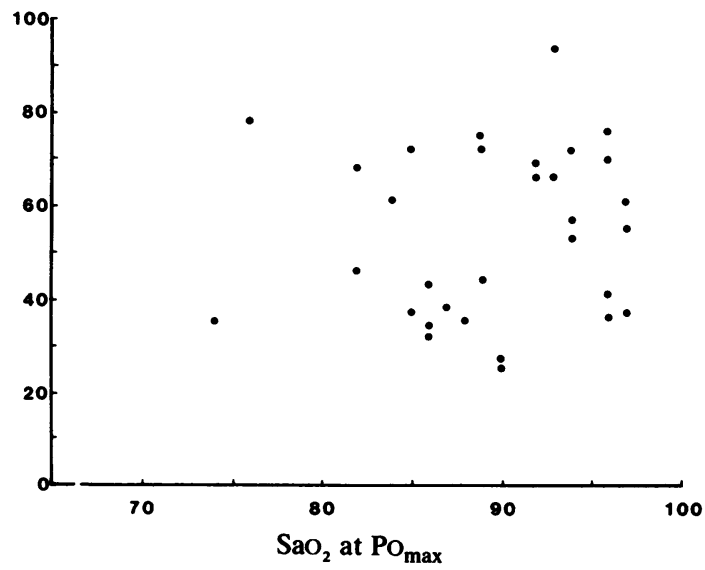

Fig 3 Arterial oxygen saturation ( $\left.\mathrm{SaO}_{2}\right)$ during exercise showing no significant association with maximum power output $\left(P O_{\max }\right)(n=31)$.

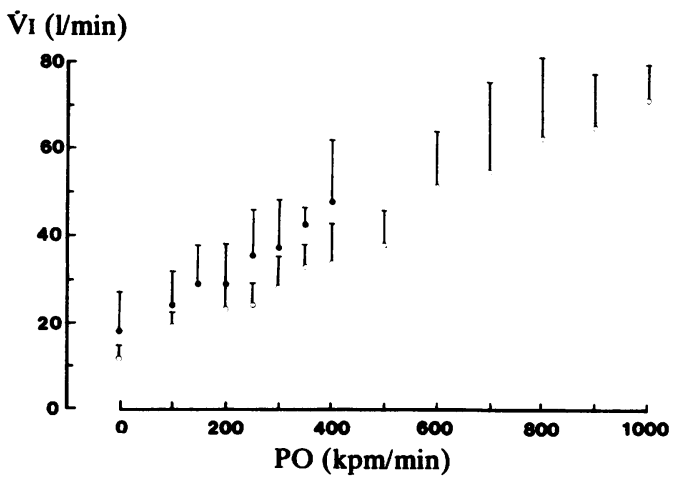

Fig 4 Mean ventilation $+S D$ at each power output $(P O)$ in those with a maximum power output ( $\left.P O_{\max }\right)$ of less than $50 \%$ of the predicted normal $(n=14: 0)$ and in those with a $P O_{\max }$ of $50 \%$ predicted or more $(n=27: 0)$.

Conversion: Traditional to SI units-Power output: 1 $\mathrm{kpm} / \mathrm{min} \approx 0.16 \mathrm{w}$. 
respiratory rate, but at all levels of $\dot{V}_{I}$ VT was smaller in patients than healthy subjects (fig 5). The tidal volume at maximum power output $\left(\mathrm{VT}_{\max }\right)$ was linearly related to VC (fig 6).

$\mathrm{Ti}$ and Ttot decreased progressively throughout exercise in the patients and healthy subjects (fig 7). The decrease in $\mathrm{Ti}$ paralleled that of Ttot, resulting in a constant $\mathrm{Ti} / \mathrm{T}$ tot ratio in patients $(0.35$ (SD $0.07)$ at rest; $0.34(0.11)$ at $\left.\mathrm{PO}_{\max }\right)$, whereas in the control subjects $\mathrm{Ti}$ decreased less than Ttot, and

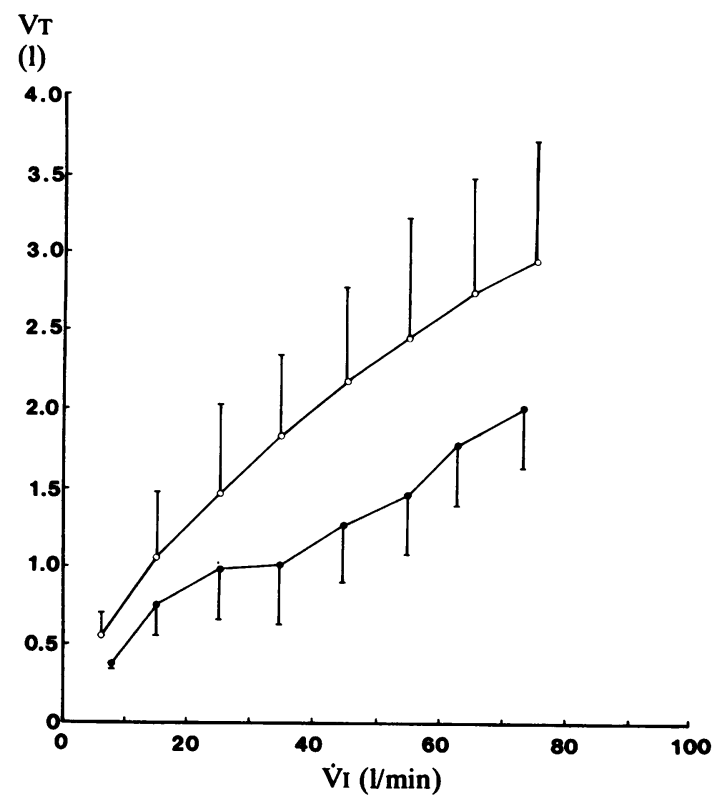

Fig 5 Tidal volume (VT) during exercise in patients (O) and matched controls (O): mean values and $1 S D$ for increments in ventilation $(\dot{V} I)$ of $10 \mathrm{l} / \mathrm{min}$.

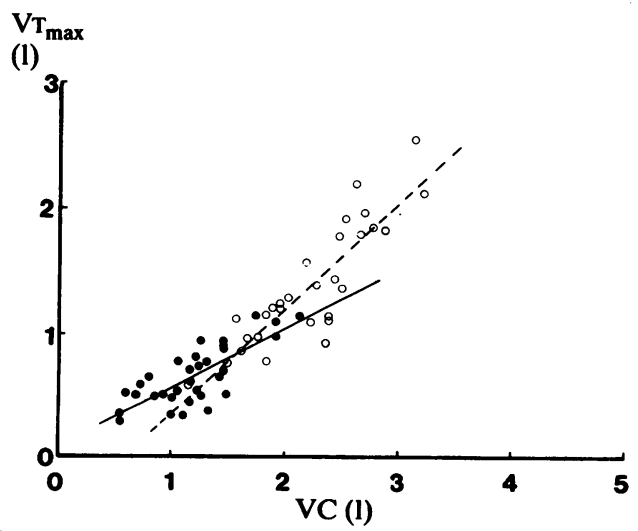

Fig 6 Maximal exercise tidal volume $\left(V T_{\max }\right)$ related to vital capacity $(V C)$ in patients (O) and controls (O). Regression equation for data on patients (-): $V T_{\text {max }}=$ $0.11+0.50 \mathrm{VC}(r=0.725, p<0.001)$.

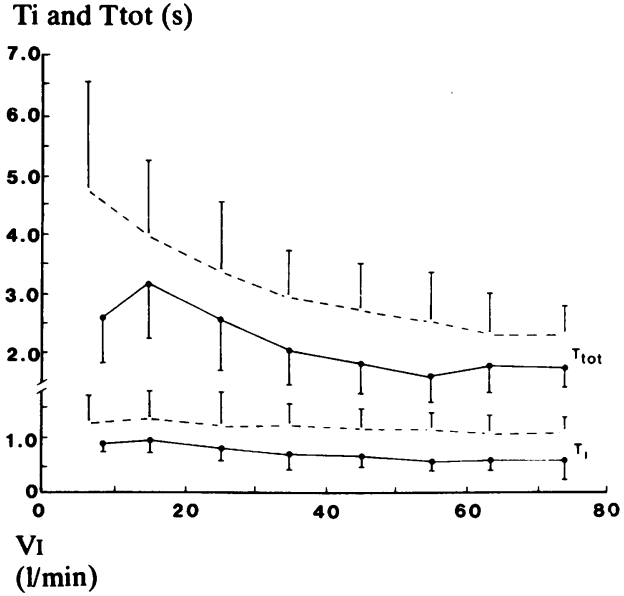

Fig 7 Inspiratory (Ti) and total breathing cycle (Ttot) duration: mean values and $1 S D$ in patients $(\bullet)$ and matched controls $(O)$ for $10 \mathrm{l} / \mathrm{min}$ increments in ventilation $(\dot{V} I)$.

Ti/Ttot showed an increase (from $0.25(0.09)$ at rest to $0.43(0.03))$. The $\mathrm{Ti} / \mathrm{T}$ tot ratio during exercise associated with VI above $401 / \mathrm{min}$ was lower in patients than in the normal subjects.

\section{Discussion}

Although there have been few formal studies of exercise limitation in diffuse pulmonary parenchymal disease, the factors underlying functional impairment are well recognised. Effort intolerance and dyspnoea are characteristic early symptoms and are related to reductions in ventilatory capacity, impaired pulmonary gas exchange, and in some patients pulmonary hypertension. Often these abnormalities combine to produce an additive effect in which impairment of exercise performance is more severe than might be expected from measurements of pulmonary function made at rest. In the present study we used maximal exercise testing to identify the relative importance of some of these factors, but our main focus was the pattern of breathing expressed in terms of the tidal volume (VT), frequency of breathing, and timing of inspiration (Ti) relative to the total respiratory cycle duration (Ttot).

Although a fall in $\mathrm{SaO}_{2}$ may be a contributory factor in exercise limitation we did not find a relationship between either the absolute $\mathrm{SaO}_{2}$ during maximum exercise (fig 3 ) or the exercise related fall in $\mathrm{SaO}_{2}$ and the reduction in maximum power output. Impairment in pulmonary oxygen transfer has been recognised as the hallmark of pulmonary 
alveolar disorders, leading to the concept of "alveolocapillary block."8 The gas exchange disturbance, which is now considered to be mainly secondary to gross dispersion of ventilation: perfusion ratios, ${ }^{9}$ was severe enough to cause a fall in $\mathrm{SaO}_{2}$ of more than $5 \%$ in 13 of the 31 patients in whom $\mathrm{SaO}_{2}$ was measured $(45 \%)$. There was no correlation between the degree of exercise oxygen desaturation and the reduction in lung volumes (VC and total lung capacity), suggesting that measurement of the change in $\mathrm{SaO}_{2}$ with exercise may help in assessing the independent effects of gas exchange disturbances in these patients. Of interest were several patients with severe oxygen desaturation who were able to achieve relatively high power outputs, the most extreme being one who reached a power output of $75 \%$ of the predicted normal value in the face of a $20 \%$ fall in $\mathrm{SaO}_{2}$. Presumably in such patients an increase in cardiac output maintains muscle oxygen delivery despite low $\mathrm{SaO}_{2}$, as occurs in normal people breathing low oxygen gas mixtures. ${ }^{10}$

Pulmonary hypertension may impair exercise performance owing to associated reductions in cardiac stroke volume and maximal cardiac output. A small stroke volume is associated with a high heart rate response to exercise, but this was found in only seven patients. Generally these patients had severe impairment of pulmonary function and severe disability as measured by the reduction in maximum power output; four showed a significant (greater than $5 \%$ ) fall in $\mathrm{SaO}_{2}$. The falls in $\mathrm{SaO}_{2}$, however, were too small to account for the increases in heart rate, ${ }^{10}$ and an impaired cardiac stroke volume response to exercise is likely to have been present in these patients.

The major factor contributing to a reduced exercise capacity was a limited ventilatory capacity. A relationship was found between maximum power output and vital capacity (fig 1); ventilation at the maximum exercise load was also correlated with the vital capacity (fig 2). Furthermore, more disabled patients showed a higher ventilatory response to exercise (fig 4), a finding which was probably influenced by oxygen desaturation on exercise and by the high dead space:tidal volume ratio which is characteristic of patients with interstitial pulmonary disorders." Thus the ventilatory impairment in exercise was a combination of an increase in the ventilation and a reduction in the ventilatory capacity to meet the demand, as reflected in the vital capacity (fig 2).

Early physiological studies of diffuse pulmonary fibrosis showed that most patients showed a low tidal volume and a high frequency pattern of breathing, seen as an adaptation for small, stiff lungs. ${ }^{211}$ In contrast, Patton and Freedman ${ }^{12}$ found normal
VT responses to carbon dioxide inhalation at rest in pulmonary fibrosis despite increases in respiratory mechanical work. In the present study the VT response to increases in ventilation was lower than in normal subjects matched for size (fig 5). The maximum VT during exercise was linearly related to vital capacity, but when the values in the patients were compared with the relationship found for the normal subjects, whose results were similar to those obtained in previous studies, ${ }^{13} 14$ many were above the normal range (fig 6). That many of our patients showed a higher $\mathrm{VT}_{\max }$ for a given $\mathrm{VC}$ than normal subjects is at first sight surprising. Such a comparison, however, contrasts patients with small lungs in a potentially normal sized thoracic cage ${ }^{15}$ with subjects in whom the size of the lungs is appropriate to that of the thoracic cage. If, as seems likely, ${ }^{15}$ the mechanical properties of the chest wall in fibrosing alveolitis are unaffected, an unusually good mechanical advantage of the inspiratory muscles may allow patients to generate a more negative pleural pressure at a given relative lung volume, thus tending to maintain VT.

Factors influencing the pattern of breathing were investigated by Clark and von Euler, ${ }^{4}$ who made measurements of the timing of the respiratory cycle in cat and man. At low levels increases in $\dot{V}_{I}$ were the result of increasing VT, the inspiratory time remaining constant ("range 1"). Subsequent increases in $\dot{V} I$ were associated with increases in VT and reductions in $\mathrm{Ti}$, with a linear relationship between VT and the reciprocal of $\mathrm{Ti}$ ("range 2"). Taken at face value the results obtained in the present studies (figs 5 and 7) suggest a shift downwards (smaller VT) and to the left (lower Ti) in the VT/Ti relationship in patients with pulmonary fibrosis, the results of patients and normal subjects lying in range 2 of Clark and von Euler. Although studies similar to those of Clark and von Euler ${ }^{4}$ have not been carried out in normal subjects with lungs as small as those of our patients, it seems reasonable to infer that a short inspiratory time and high respiratory rate (short Ttot) are adopted as a response to the elastic load presented by stiff lungs.

Inspiratory elastic loads in healthy subjects usu- $N$ ally, ${ }^{1617}$ but not always, ${ }^{18}$ are associated with increases in respiratory rate and reductions in tidal volume. Although few studies have reported $\mathrm{Ti} / \mathrm{C}$ Ttot, this ratio may be calculated from the results presented by Agostoni and colleagues ${ }^{19}$; elastic load- -0 ing progressively reduced $\mathrm{Ti}$, but the $\mathrm{Ti} / \mathrm{Tt}$ tot ratio $\underset{\infty}{\Phi}$ remained constant in their subjects studied during $\cdot$ carbon dioxide breathing. The responses to elastic ${ }^{0}$ loading have also been studied in normal subjects $\frac{O}{\mathbb{D}}$ undergoing cycle ergometer exercise ${ }^{20}$; all subjects $\cong$ showed a low VT at a given Vir. In patients with $\stackrel{\unrhd}{\varrho}$ 
pulmonary fibrosis at rest, during $5 \%$ carbon dioxide breathing ${ }^{12}$ and during exercise, ${ }^{214}$ a low VT, high frequency pattern of breathing has been found and usually ascribed to stimulation of pulmonary irritant or stretch receptors. Bradley and Crawford ${ }^{14}$ reported that $\mathrm{Ti} / \mathrm{Ttot}$ at high levels of ventilation during exercise was about 0.5 in normal subjects and 0.4 in patients with restrictive diseases. In our subjects $\mathrm{Ti}$ decreased progressively with increasing $\hat{V}_{\mathbf{I}}$ up to $40 \mathrm{l} / \mathrm{min}$, but changed little at higher levels (fig 7); Ti was about one second less at all exercise levels in the patients than in the normal subjects. The average inspiratory flow (VT/Ti) was similar in the patients and controls at all levels of exercise, reaching about $3.5 \mathrm{l} / \mathrm{s}$ at the higher levels of VI. If, however, these flow rates are considered in relation to the lung volume at which they were generated, the possibility arises that maximum inspiratory flows were reached ${ }^{21}$ by the patients.

The depth and rate of breathing normally are linked to maintain normal gas exchange at a minimal cost in terms of respiratory muscle force ${ }^{22}$ and work. ${ }^{23}$ The receptors which signal the increase in respiratory muscle force to enable this adaptive response have been the subject of speculation; but recent research which has quantified the sense of respiratory effort in response to elastic loading of the inspiratory muscles suggests that there may be a behavioural or "learned" component to the mechanisms concerned.

The increased elastance associated with pulmonary fibrosis imposes an impedance to the action of the inspiratory muscles; the peak inspiratory force is the product of the tidal volume and the elastance of the respiratory system. The maintenance of a given tidal volume in the face of high elastance requires a large peak intensity of inspiratory force which could result in diaphragm fatigue, despite normal maximal respiratory muscle power. ${ }^{24}$ Thus the pattern of breathing adopted in our patients, with reduced tidal volume, was that expected to reduce peak force and delay the onset of fatigue.

The reduction in peak force was accompanied by an increase in the frequency of force development - that is, in the respiratory rate-and a reduction in Ttot, an adaptation which will tend to increase the total force developed. Nevertheless, a shortening of the duration of force development in each breath (reduction in Ti/Ttot, fig 7) served to minimise the total force generated by respiratory muscles over a given time and maximise the ability of the respiratory muscles to maintain force development without fatigue..$^{25}$

When inspiratory elastic loads are presented to healthy subjects, their perception of the magnitude of the added elastance is only indirectly related to the actual size of the elastance, and directly related to the effort generated against the load. ${ }^{26}{ }^{27}$ The perceived magnitude $(\psi)$ bears a power function to both the intensity (P) and the duration ( $t)$ of force development as expressed in the equation ${ }^{26}$

$$
\psi=\mathrm{K}_{0} \times \mathrm{P}^{1.3} \times \mathrm{t}^{0.56} .
$$

Thus by minimisation of the peak intensity of force and the time for which it is sustained the perceptual magnitude of the load is also minimised. The results of these sensory experiments suggest that the pattern of force development by inspiratory muscles may be behaviourally selected in the light of sensory information regarding the impedance to breathing. Thus patients with pulmonary fibrosis, when faced with the increased breathing demands of exercise, minimise the peak intensity of force (smaller VT), the duration of force development (shorter Ti) and the time spent in force development in relation to the time of recovery (decreased Ti/Ttot). This pattern may be selected or conditioned as a behavioural response rather than on the basis of reflex mechanisms.

We are grateful to Dr $\mathbf{J}$ Morse for permitting us to study records of exercise studies carried out in the regional chest and allergy unit at St Joseph's Hospital. Dr JGW Burdon held a fellowship in applied health sciences (National Health and Medical Research Council, Australia).

\section{References}

${ }^{1}$ Jones NL. Exercise testing in pulmonary evaluation: clinical applications. $N$ Engl J Med 1975;293:647-9.

${ }^{2}$ Kaltreider NL, McCann WS. Respiratory response during exercise in pulmonary fibrosis and emphysema. $J$ Clin Invest 1937;16:23-40.

${ }^{3}$ Hey EN, Lloyd BB, Cunningham DJC, Jukes MGM, Bolton DPG. Effects of various respiratory stimuli on the depth and frequency of breathing man. Respir Physiol 1966;1:193-205.

${ }^{4}$ Clark FJ, von Euler C. On the regulation of depth and rate of breathing. J Physiol (Lond) 1972;222:267-95.

${ }^{5}$ Morris JF, Koski A, Johnson LC. Spirometric standards for healthy non-smoking adults. Am Rev Respir Dis 1971;103:57-67.

6 Jones NL, Campbell EJM. Clinical exercise testing. 2nd ed. Philadelophia: WB Saunders, 1982.

7 Saunders NA, Powles ACP, Rebuck AS. Ear oximetry: accuracy and practicability in the assessment of arterial oxygenation. Am Rev Respir Dis 1976;113:745-9.

${ }^{8}$ Austrian R, McClement JH, Renzetti AD, Donald KW, Riley RL, Cournand A. Clinical and physiological features of some types of pulmonary disease with impairment of alveolo-capillary diffusion: the syndrome of alveolo-capillary block. Am J Med 1951;11:667-85. 
${ }^{9}$ Staub NC. Alveolar-arterial oxygen tension gradient due to diffusion. J Appl Physiol 1963;18:673-80.

${ }^{10}$ Hughes RL, Clode M, Edwards RHT, Goodwin TJ, Jones NL. Effect of inspired $\mathrm{O}_{2}$ on cardiopulmonary and metabolic responses to exercise in man. $J$ Appl Physiol 1968;24:336-47.

"Lourenco RV, Turino GM, Davidson LAG, Fishman AP. The regulation of ventilation in diffuse pulmonary fibrosis. Am J Med 1965;38:199-216.

12 Patton JMS, Freedman S. The ventilatory response to $\mathrm{CO}_{2}$ of patients with diffuse pulmonary infiltrations or fibrosis. Clin Sci 1972;43:55-69.

13 Jones NL, Rebuck AS. Tidal volume during exercise in patients with diffuse fibrosing alveolitis. Bull Europ Physiopath Respir 1979;15:321-7.

${ }^{14}$ Bradley GW, Crawford R. Regulation of breathing during exercise in normal subjects and in chronic lung disease. Clin Sci Mol Med 1976;51:575-82.

15 Gibson GJ, Pride NB. Pulmonary mechanics in fibrosing alveolitis. The effects of lung shrinkage. Am Rev Respir Dis 1977;116:637-47.

${ }^{16}$ Bland S, Lazerou L, Dyck G, Cherniack RM. The influence of the "chest wall" on respiratory rate and depth. Respir Physiol 1967;3:47-54.

${ }^{17}$ Margaria CE, Iscoe S, Pengelly LD, Couture J, Don J, Milic-Emili J. Immediate ventilatory response to elastic load and positive pressure in man. Respir Physiol 1973;18:347-69.

${ }^{18}$ Pope H, Holloway R, Campbell EJM. The effects of elastic and resistive loading of inspiration on the breathing of conscious man. Respir Physiol 1968;4: 363-72.
${ }^{19}$ Agostoni E, D' Angelo E, Piolini M. Breathing pattern in man during inspiratory elastic loads. Respir Physiol $\stackrel{\Omega}{S}$ 1978;34:279-93.

${ }^{20}$ Cotes JE, Johnson-GR, McDonald A. Breathing frequency and tidal volume: relationship to breath- $\bar{c}$

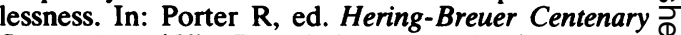
Symposium. (Ciba Foundation symposium). London: $\varrho$ Churchill, 1970;297-314.

${ }^{21}$ Jordanaglou J, Pride NB. A comparison of maximum inspiratory and expiratory flow in health and in lung. disease. Thorax 1968;23:38-45.

${ }^{22}$ Mead J. Control of respiratory frequency.J Appl Physiol $\vec{\omega}$ 1960;15:325-36.

${ }^{23}$ Otis AB, Fenn WO, Rahn H. Mechanics of breathing in man. J Appl Physiol 1950;2:592-607.

${ }^{24}$ De Troyer A, Yernault JC. Inspiratory muscle force in normal subjects and patients with interstitial lung dis- $\vec{O}$ ease. Thorax 1980;35:92-100.

${ }^{25}$ Roussos CS, Macklem PT. Diaphragmatic fatigue in $ळ$

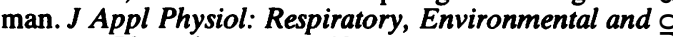
Exercise Physiology 1977;43:189-97.

${ }^{26}$ Killian KJ, Bucens DD, Campbell EJM. Effect of breathing pattern on the perceived magnitude of added loads to breathing. J Appl Physiol: Respiratory, Environmental and Exercise Physiology 1982;52:578-84.

${ }^{27}$ Burdon JGW, Killian KJ, Campbell EJM. Effect of ven- $\vec{\theta}$ tilatory drive on the perceived magnitude of added $\omega_{\omega}^{\infty}$ loads to breathing. J Appl Physiol: Respiratory, Environmental and Exercise Physiology 1982;53:901-7. 